\title{
АНАЛИЗ ОТЛОЖЕНИЙ НЕОРГАНИЧЕСКИХ СОЛЕЙ В СИСТЕМЕ СБОРА НСП «Б», ДНС-5 «А»
}

\author{
Яркеева Наталья Расатовна', \\ yarkeevan@yandex.ru
}

\author{
Галкова Алсу Фаузитовна', \\ alsugalkova1995@mail.ru
1 Уфимский государственный нефтяной технический университет, Россия, 450062, Уфа, ул. Космонавтов, 1.

Актуальность. В настоящее время проблема образования отложения солей очень актуальна и важна. Добыча нефти затрудняется с появлением неорганических отложений, которые образуются в призабойной зоне скважин и в системах сбора и подготовки скважинной продукции. Последствием отложения солей является снижение коэффициента продуктивности скважин, из-за чего происходит значительная потеря нефти. Также по причине недостаточного притока возникает риск отказа глубинно-насосного оборудования, происходит снижение наработки на отказ этого оборудования из-за того, что возникают заклинивания электроприводного центробежного насоса и клапанов штангового глубинного насоса. По этим причинам нефтяные компании терпят значительные убытки, так как возникает необходимость больших затрат на мероприятия по предупреждению и борьбе с солевыми отложениями.

Цель. Определить методы предупреждения отложений и методы борьбы с ними. Выяснить будет ли выпадать осадок в результате определения коэффициента пересыщения $\varphi$ по методике Скилмена-Мак-Дональда-Стиффа. Провести анализ исследований по определению компонентного состава отложений.

Методы. При проведении расчетов использовалась методика Скилмена-Мак-Дональда-Стиффа. Неорганическая часть отложений определялась методом рентгеновской дифрактометрии на порошковом дифрактометре Shimadzu XRD-6000.

Результаты. Анализ результатов определения макро- и микрокомпонентного состава вод показал, что в пробах попутно-добываемых вод, отобранных с добывающих скважин и автоматизированные групповые замерные установки месторождения X, содержится существенное количество ионов кальция и сульфат-ионов, что может привести к образованию отложений нерастворимых солей, таких как кальцит и гипс. В скважинах под номерами 5 и 311 коэффициент пересыщения $\varphi>1$ (существует пересыщенность пластовой воды гипсом). В этих скважинах гипс имеет возможность выпадать и в объеме, и на самой поверхности теплообмена. В скважине под номером 158 коэффициент пересыщения $\varphi<1$. При ненасыщенности им пластовой воды выпадение осадка в объеме не будет. Однако на поверхности теплообмена, вследствие частичного выпаривания раствор особо насыщается гипсом. Из-за этого гипс способен откладываться и при некоторой недонасыщенности им пластовой воды - при понижение коэффициента $\varphi$ до 0,9. Чтобы отложения гипса не осложняли добычу нефти, нужно заранее предупреждать образования отложений. Для предотвращения образования отложений необходимо подобрать эффективный ингибитор солеотложений для условий месторождений, осуществляющих сбор на НСП «Б». С целью защиты системы нефтесбора рекомендуется организовать подачу ингибитора солеотложений.

\section{Ключевые слова:}

Отложения, выпадение осадка, неорганические соли, кальцит, гипс, ингибитор солеотложений.

\section{Введение}

В лаборатории института проведены исследования по определению компонентного состава отложений с площадного объекта НСП «Б» и напорного нефтепровода ДНС-5 «А» - НСП «Б» (табл. 1).

На рис. 1, 2 представлен внешний вид отложений до (а) и после (б) отмывки органическим растворителем.

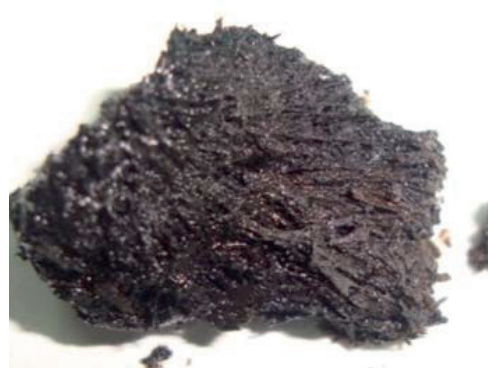

$a / a$
Содержание органической и неорганической частей осадков с НСП «Б» представлено в табл. 1.

Отложения, отобранные на НСП «Б» НГДУ, представляли собой смесь органической (углеводородной) $(15,9-33,9 \%)$ и неорганической частей (66,1-84,1 \% ). Отложения, отобранные со сборных и напорных трубопроводов, представляют собой смесь органической (углеводородной) (5,1-10,2%) и неорганической частей $(89,8-94,9 \%)$.

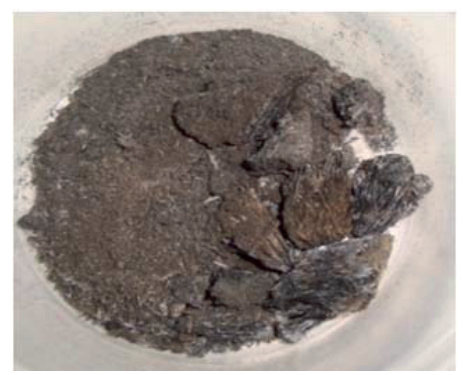

$\sigma / b$

Pис. 1. Отложения, отобранные со входа НСП «Б»

Fig. 1. Deposits selected from the entrance of the NSP «B» 


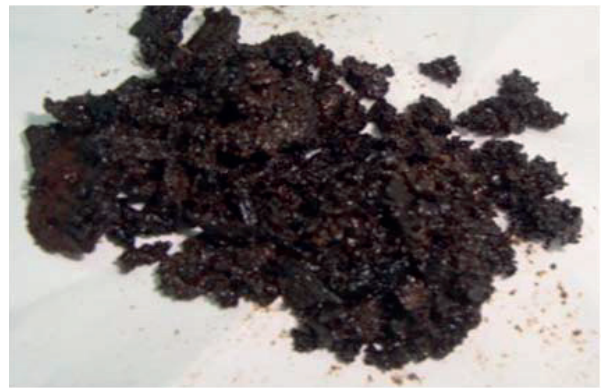

$a / a$

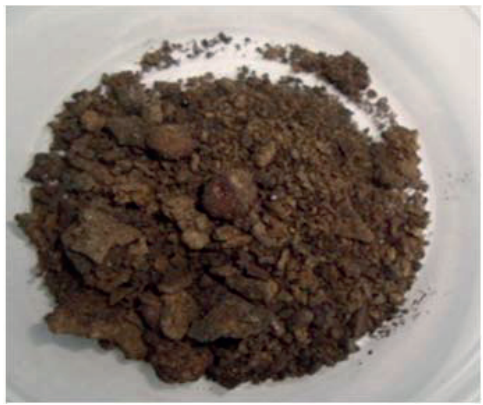

$\sigma / b$

Рис. 2. Отложения, отобранные с теплообменника НСП «Б»

Fig. 2. Deposits selected from the heat exchanger NSP «B»

таблица 1. Содержание неорганической и органической частей осадков в отобранных отложениях

Table 1. Content of inorganic and organic parts in the selected sediments

\begin{tabular}{|c|c|c|c|}
\hline \multirow[b]{2}{*}{$\begin{array}{l}\text { Наименование объекта } \\
\text { Name of object }\end{array}$} & \multirow[b]{2}{*}{$\begin{array}{c}\text { Дата отбора } \\
\text { Date } \\
\text { of selection }\end{array}$} & \multicolumn{2}{|c|}{ Содержание/Contents, \% } \\
\hline & & $\begin{array}{l}\text { Неорганичес- } \\
\text { кая часть } \\
\text { Inorganic part }\end{array}$ & $\begin{array}{c}\text { Органическая } \\
\text { часть } \\
\text { Organic part }\end{array}$ \\
\hline $\begin{array}{l}\text { Отложения } \\
\text { с трубопровода (вход 0-1) } \\
\text { Deposits from the } \\
\text { pipeline (0-1 inlet) }\end{array}$ & 18.03 .18 & 66,1 & 33,9 \\
\hline $\begin{array}{l}\text { Отложения } \\
\text { с трубопровода } \\
\text { (теплообменники 0-1) } \\
\text { Deposits from } \\
\text { the pipeline } \\
\text { (0-1 heat exchangers) }\end{array}$ & 18.03.18 & 84,1 & 15,9 \\
\hline $\begin{array}{l}\text { Отложения } \\
\text { с технологических } \\
\text { трубопроводов HCП «Б» } \\
\text { Deposits from technologi- } \\
\text { cal pipelines of NSP «B» }\end{array}$ & 29.03 .18 & 68,2 & 31,8 \\
\hline $\begin{array}{l}\text { Отложения с напорного } \\
\text { нефтепровода } \\
\text { ДНС-5 «А»- НCП «Б» } \\
\text { Deposits on the pressure } \\
\text { of the pipeline } \\
\text { BPS-5 «A»- NSP «B» }\end{array}$ & 13.07 .18 & 94,9 & 5,1 \\
\hline $\begin{array}{l}\text { Отложения с трубопрово- } \\
\text { да АГЗУ } 258 \text { - ДНС «А» } \\
\text { Deposits from the pipeli- } \\
\text { ne AGZU 258- BPS-5 «A» }\end{array}$ & 28.09 .18 & 89,8 & 10,2 \\
\hline
\end{tabular}

С трубопровода ДНС- 5 «А» - НCП «Б» и с трубопровода АГЗУ 258 - ДНС «А» отложения состоят из органической (углеводородной) $(5,1-10,2 \%$ ) и неорганической частей $(89,8-94,8 \%)$.

В табл. 2 приведен компонентный состав неорганической части отложений.

Неорганическая часть отложений с входа в 0-1 НСП «Б», с технологических трубопроводов НСП «Б», с напорного нефтепровода ДНС-5 «А»-НСП «Б» состоит из сульфата кальция (гипса Са$\mathrm{SO}_{4} \cdot 2 \mathrm{H}_{2} \mathrm{O}$ и бассанита $\mathrm{CaSO}_{4} \cdot 0,5 \mathrm{H}_{2} \mathrm{O}$ ) с его содержанием $97,5-100 \%$. Неорганическая часть отложений с теплообменника 0-1 НCП «Б» состоит преимущественно из карбоната кальция (кальцит, $\mathrm{Ca}$ $\mathrm{CO}_{3}$ ) с его содержанием $68,1 \%$.

Для неорганической части отложений определен компонентный состав методом рентгеновской дифрактометрии, на порошковом дифрактометре Shimadzu XRD-6000. Процентное соотношение компонентов рассчитывалось при помощи программного обеспечения SiroQuant [1-3].

Лабораторный опыт по отмывке проводился на осадках, отобранных с трубопровода на входе в 0-1 (преимущественно представлен гипсом) и на осадке с теплообменника 0-1 (преимущественно представлен кальцитом).

В условиях лаборатории для удаления отложений были опробованы водные растворы гидроксида натрия $(20 \%)$ и ингибированной соляной кислоты $(8 \%)$. Раствором щелочи и кислоты пробы

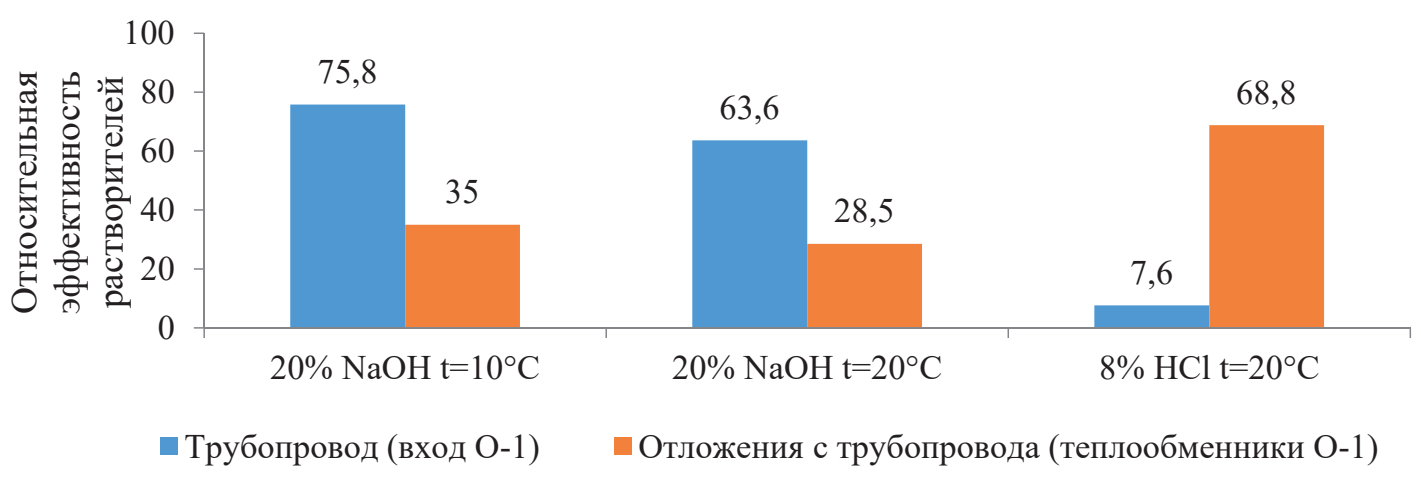

Рис. 3. Относительная эффективность водных растворов гидроксида натрия и ингибированной соляной кислоты

Fig. 3. Relative effectiveness of aqueous solutions of sodium hydroxide and inhibited hydrochloric acid 
Таблица 2. Компонентный состав неорганической части отобранных отложений

Table 2. $\quad$ Component composition of inorganic part of selected sediments

\begin{tabular}{|c|c|c|c|}
\hline \multirow{2}{*}{$\begin{array}{c}\text { Место отбора } \\
\text { Place of selection }\end{array}$} & \multirow{2}{*}{$\begin{array}{c}\text { Дата } \\
\text { отбора } \\
\text { Selection } \\
\text { date }\end{array}$} & \multicolumn{2}{|c|}{$\begin{array}{l}\text { Компонентный состав неорганической части отложений } \\
\text { Component composition of inorganic part of sediments }\end{array}$} \\
\hline & & $\begin{array}{c}\text { Соединение } \\
\text { Compound }\end{array}$ & $\begin{array}{l}\text { Содержание, \% } \\
\text { Content, \% }\end{array}$ \\
\hline \multirow{2}{*}{$\begin{array}{l}\text { Трубопровод (вход 0-1) } \\
\text { Pipeline (0-1 inlet) }\end{array}$} & \multirow{2}{*}{18.03 .18} & $\begin{array}{l}\text { Дигидрат сульфата кальция (гипс, } \mathrm{CaSO}_{4} \cdot 2 \mathrm{H}_{2} \mathrm{O} \text { ) } \\
\text { Calcium sulfate dihydrate (gypsum, } \mathrm{CaSO}_{4} \cdot 2 \mathrm{H}_{2} \mathrm{O} \text { ) }\end{array}$ & 54,0 \\
\hline & & $\begin{array}{c}\left.\text { Полугидрат сульфата кальция (бассанит, } \mathrm{CaSO}_{4} \cdot 0,5 \mathrm{H}_{2} \mathrm{O}\right) \\
\text { Calcium sulfate semihydrate (bassanite, } \mathrm{CaSO}_{4} \cdot 0,5 \mathrm{H}_{2} \mathrm{O} \text { ) }\end{array}$ & 46,0 \\
\hline \multirow{4}{*}{$\begin{array}{l}\text { Отложения с трубопровода (теплообменники 0-1) } \\
\text { Deposits from the pipeline (0-1 heat exchangers) }\end{array}$} & \multirow{4}{*}{18.03 .18} & $\begin{array}{c}\text { Карбонат кальция (кальцит, } \mathrm{CaCO}_{3} \text { ) } \\
\text { Calcium carbonate (calcite, } \mathrm{CaCO}_{3} \text { ) }\end{array}$ & 68,1 \\
\hline & & $\begin{array}{l}\text { Дигидрат сульфата кальция (гипс, } \mathrm{CaSO}_{4} \cdot 2 \mathrm{H}_{2} \mathrm{O} \text { ) } \\
\text { Calcium sulfate dihydrate (gypsum, } \mathrm{CaSO}_{4} \cdot 2 \mathrm{H}_{2} \mathrm{O} \text { ) }\end{array}$ & 19,2 \\
\hline & & $\begin{array}{c}\text { Натрий хлористый }(\mathrm{NaCl}) \\
\text { Sodium chloride }(\mathrm{NaCl})\end{array}$ & 7,4 \\
\hline & & $\begin{array}{l}\text { Оксид кремния (кварц, } \mathrm{SiO}_{2} \text { ) } \\
\text { Silicon oxide (quartz, } \mathrm{SiO}_{2} \text { ) }\end{array}$ & 5,4 \\
\hline \multirow{5}{*}{$\begin{array}{l}\text { Отложения с технологических трубопроводов НСП «Б» } \\
\text { Deposits from PS process pipelines NSP «B» }\end{array}$} & \multirow{5}{*}{29.03 .18} & $\begin{array}{l}\text { Дигидрат сульфата кальция (гипс, } \mathrm{CaSO}_{4} \cdot 2 \mathrm{H}_{2} \mathrm{O} \text { ) } \\
\text { Calcium sulfate dihydrate (gypsum, } \mathrm{CaSO}_{4} \cdot 2 \mathrm{H}_{2} \mathrm{O} \text { ) }\end{array}$ & 75,4 \\
\hline & & $\begin{array}{c}\text { Карбонат кальция (кальцит, } \mathrm{CaCO}_{3} \text { ) } \\
\text { Calcium carbonate (calcite, } \mathrm{CaCO}_{3} \text { ) }\end{array}$ & 12,3 \\
\hline & & $\begin{array}{l}\text { Натрий хлористый }(\mathrm{NaCl}) \\
\text { Sodium chloride }(\mathrm{NaCl})\end{array}$ & 6,1 \\
\hline & & $\begin{array}{l}\text { Оксид кремния (кварц, } \mathrm{SiO}_{2} \text { ) } \\
\text { Silicon oxide (quartz, } \mathrm{SiO}_{2} \text { ) }\end{array}$ & 4,1 \\
\hline & & $\begin{array}{c}\text { Сульфид железа (FeS) } \\
\text { Iron sulfide (FeS) }\end{array}$ & 2,2 \\
\hline \multirow{2}{*}{$\begin{array}{c}\text { Отложения трубопровода ДНС-5 A - НСП Б } \\
\text { Deposits of pipeline DNS-5 A-NSP B }\end{array}$} & \multirow{2}{*}{13.07 .18} & $\begin{array}{l}\left.\text { Дигидрат сульфата кальция (гипс } \mathrm{CaSO}_{4} \cdot 2 \mathrm{H}_{2} \mathrm{O}\right) \\
\text { Calcium sulfate dihydrate }\left(\mathrm{CaSO}_{4} \cdot 2 \mathrm{H}_{2} \mathrm{O} \text { gypsum) }\right.\end{array}$ & 97,5 \\
\hline & & $\begin{array}{l}\text { Натрий хлористый }(\mathrm{NaCl}) \\
\text { Sodium chloride }(\mathrm{NaCl})\end{array}$ & 2,5 \\
\hline \multirow{3}{*}{$\begin{array}{l}\text { Отложения с трубопровода АГЗУ } 258 \text { - ДНС «А» } \\
\text { Deposits from the pipeline AGZU 258-DNS «A» }\end{array}$} & \multirow{3}{*}{28.09 .18} & $\begin{array}{l}\text { Дигидрат сульфата кальция (гипс, } \mathrm{CaSO}_{4} \cdot 2 \mathrm{H}_{2} \mathrm{O} \text { ) } \\
\text { Calcium sulfate dihydrate (gypsum, } \mathrm{CaSO}_{4} \cdot 2 \mathrm{H}_{2} \mathrm{O} \text { ) }\end{array}$ & 97,5 \\
\hline & & $\begin{array}{l}\text { Оксид кремния (кварц, } \mathrm{SiO}_{2} \text { ) } \\
\text { Silicon oxide (quartz, } \mathrm{SiO}_{2} \text { ) }\end{array}$ & 1,3 \\
\hline & & $\begin{array}{l}\text { Натрий хлористый }(\mathrm{NaCl}) \\
\text { Sodium chloride }(\mathrm{NaCl})\end{array}$ & 1,2 \\
\hline
\end{tabular}

отложений обрабатывали в течение 4 часов при температурах +10 и $+20{ }^{\circ} \mathrm{C}$, массовое соотношение исследуелый образеи: реагент составило 1:10. По истечении 4 часов эксперимента осадок переносился на фильтр "синяя» лента и промывался дистиллированной водой до значения $\mathrm{pH}$ 6,6.

Результат обработки отложений растворами щелочей и кислот представлен в табл. 3 и на рис. 3.

Таблица 3. Относительная эффективность растворителей по отношению к отложениям

Table 3. Relative efficiency of solvents in relation to sediments

\begin{tabular}{|c|c|c|c|}
\hline $\begin{array}{c}\text { Наименование образца } \\
\text { Sample name }\end{array}$ & $\begin{array}{c}20 \% \mathrm{NaOH} \\
t=10{ }^{\circ} \mathrm{C}\end{array}$ & $\begin{array}{c}20 \% \mathrm{NaOH} \\
t=20{ }^{\circ} \mathrm{C}\end{array}$ & $\begin{array}{c}8 \% \mathrm{HCl} \\
t=20{ }^{\circ} \mathrm{C}\end{array}$ \\
\hline $\begin{array}{c}\text { Вход 0-1 (гипс) } \\
\text { 0-1 entrance (gypsum) }\end{array}$ & 76 & 64 & 8 \\
\hline $\begin{array}{c}\text { Tеплобоменник 0-1 (кальцит) } \\
\text { Неat exchangers-1 (calcite) }\end{array}$ & 35 & 29 & 69 \\
\hline
\end{tabular}

Из лабораторных исследований следует, что при температуре $20{ }^{\circ} \mathrm{C}$ диспергирование гипса в $20 \%$-м растворе гидроксида натрия составляет $64 \%$, тогда как в растворе соляной кислоты $8 \%$. Для осадка, представленного преимуще- ственно кальцитом, соляная кислота, наоборот, обладает большей эффективностью (69 \% ) по сравнению с 20 \% -м гидроксидом натрия (29\%).

Для выявления причин образования отложений в системе сбора месторождения X в напорных нефтепроводах ДНС-5 «А»- НСП «Б» был проведен анализ макрокомпонентного состава попутнодобываемых вод (табл. 4).

Анализ результатов определения макро- и микрокомпонентного состава вод показал, что в пробах попутно-добываемых вод, отобранных с добывающих скважин и АГЗУ месторождения X, содержится существенное количество ионов кальция и сульфат-ионов, что может привести к образованию отложений нерастворимых солей, таких как кальцит и гипс. Исходя из табл. 2, основным осадком здесь является дигидрат сульфата кальция (гипс $\left.\mathrm{CaSO}_{4} \cdot 2 \mathrm{H}_{2} \mathrm{O}\right)$ [4-8].

Произведем расчет коэффициента пересыщения $\varphi$ в трех добывающих скважинах № 5, 158 и 311.

Для определения выпадения осадка расчет будем вести по методике Скилмена-Мак Дональда-Стиффа. Суть этого способа заключается в том, 
Известия Томского политехнического университета. Инжиниринг георесурсов. 2019. Т. 330. № 7. 123-129

Яркеева Н.Р., Галкова А.Ф. Анализ отложений неорганических солей в системе сбора НСП "Б", ДНС-5 "А"

Таблица 4. Макро- и микрокомпонентый состав попутно-добываелых вод из добывающих скважин месторождения X

Table 4. Macro- and microcomponent composition of associated-produced water from production wells of the $X$ deposit

\begin{tabular}{|c|c|c|c|c|c|c|c|c|c|c|c|c|}
\hline \multirow{2}{*}{$\begin{array}{c}\text { Точка отбора } \\
\text { (скважина) } \\
\text { Selection point } \\
\text { (well) }\end{array}$} & \multirow{2}{*}{$\begin{array}{l}\text { Пласт } \\
\text { Layer }\end{array}$} & \multirow{2}{*}{$\begin{array}{c}\text { Дата отбора } \\
\text { Selection } \\
\text { date }\end{array}$} & \multicolumn{8}{|c|}{ 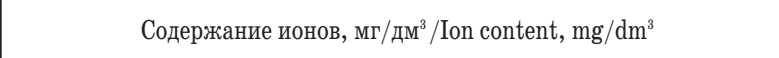 } & \multirow{2}{*}{$\begin{array}{c}\text { pH, } \\
\text { ед./unit }\end{array}$} & \multirow{2}{*}{ 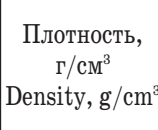 } \\
\hline & & & $\mathrm{Cl}^{-}$ & $\mathrm{SO}_{4}{ }^{2-}$ & $\mathrm{HCO}_{3}^{-}$ & $\mathrm{Ca}^{2+}$ & $\mathrm{Mg}^{2+}$ & $\mathrm{Na}^{+}+\mathrm{K}^{+}$ & $\mathrm{Sr}^{2+}$ & $\mathrm{Ba}^{2+}$ & & \\
\hline 5 & \multirow{2}{*}{ СТкиз/STkiz } & 09.04 .2018 & 151566,5 & 2864 & 225,7 & 4671,3 & 1072,5 & 96421,6 & 86 & $<1,0$ & 6,9 & 1,178 \\
\hline 158 & & 05.12 .2018 & 185446 & 1136 & 122 & 6513 & 1672 & 115064 & - & - & 6,3 & 1,191 \\
\hline 311 & $\begin{array}{l}\text { Dмул, Dпаш } \\
\text { Dmul, Dpash }\end{array}$ & 05.12 .2018 & 169397,8 & 319 & 67,1 & 38326,5 & 3800 & 61469,9 & - & - & 5,5 & 1,185 \\
\hline
\end{tabular}

Таблица 5. Результаты расчетов трех добывающих скважин 5, 158, 311

Table 5. Results of three producing well 5, 158, 311

\begin{tabular}{|c|c|c|c|c|c|c|}
\hline $\begin{array}{c}\text { № скважины } \\
\text { Well no. }\end{array}$ & $\begin{array}{c}\text { Фактическая концен- } \\
\text { трация, C, мг-экв/л } \\
\text { Actual concentration, } \\
\text { C, mg-eq/l }\end{array}$ & $\begin{array}{c}\text { Избыточная концен- } \\
\text { трация X, мг/л } \\
\text { Excess concentration, } \\
\text { X, mg/l }\end{array}$ & $\begin{array}{c}\text { Ионная сила ра- } \\
\text { створа, I, мг/л } \\
\text { Ionic solution } \\
\text { strength, I, mg/l }\end{array}$ & $\begin{array}{l}\text { Константа ра- } \\
\text { створимости } \\
\text { Solubility con- } \\
\text { stant } \mathrm{K} \times 10^{-4} \\
\end{array}$ & $\begin{array}{c}\text { Равновесная концен- } \\
\text { трация, } C^{p}, \text { мг-экв/л } \\
\text { Equilibrium concentra- } \\
\text { tion } C^{\mathrm{p}}, \mathrm{mg} \text {-eq } / \mathrm{l}\end{array}$ & $\begin{array}{c}\text { Коэффициент пе- } \\
\text { ресыщения, } \varphi \\
\text { Supersaturation } \\
\text { factor, } \varphi \\
\end{array}$ \\
\hline 5 & 59,66667 & 0,086997 & 4,626666 & 26,43 & 47,68963 & 1,251146 \\
\hline 158 & 23,66667 & 0,151011 & 5,615238 & 21,27 & 25,94194 & 0,912294 \\
\hline 311 & 6,645833 & 0,954845 & 5,959068 & 19,35 & 4,044449 & 1,643199 \\
\hline
\end{tabular}

что определяется равновесная концентрация сульфата кальция и сопоставляется с фактической концентрацией сульфата кальция в пластовых или попутно-добываемых водах $[9,10]$.

Склонность пластовой воды к отложению гипса оценивается по коэффициенту пересыщения:

$$
\varphi=\frac{C_{\mathrm{CaSo}_{4}}}{C_{\mathrm{CaSo}_{4}}^{p}},
$$

где $C_{\mathrm{CaS04}}$ - фактическая концентрация гипса в пластовой воде, которая определяется по концентрации того иона $\mathrm{Ca}^{2+}$ или $\mathrm{SO}_{4}^{2-}$, присутствовавшего в меньшем количестве, мг-экв/л; $C_{\mathrm{CaSO}_{4}}^{p}-$ равновесная концентрация гипса в пластовой воде, мг-экв/л. Результаты расчетов представлены в табл. 5. По проведенным расчетам можно сделать следующие выводы. В скважинах № 5 и 311 коэффициент пересыщения $\varphi>1$, при пересыщенности пластовой воды гипсом это означает, что в этих скважинах гипс может выпадать и в объеме, и на самой поверхности теплообмена. В скважине № 158 коэффициент пересыщения $\varphi<1$, при ненасыщенности им пластовой воды выпадение осадка в объеме не будет. Однако на поверхности теплообмена вследствие частичного выпаривания раствор особо насыщается гипсом. Из-за этого гипс способен откладываться при некоторой недонасыщенности им пластовой воды при понижение коэффициента $\varphi$ до 0,9 .

\section{Заключение}

Для того чтобы отложения гипса не осложняли добычу нефти, нужно заранее предупреждать их образование физическими, технологическими и химическими методами [11-14]. Физические методы предупреждения заключаются в воздействии на продукцию: магнитным полем, электромагнитным полем, акустическим полем и токами высокой частоты. $К$ технологическим методам относят применение низкоадгезионных защитных покрытий $\mathrm{BCO}$, изменение технических режимов работы скважин и насосного оборудования, турбулизацию потоков, применение хвостовиков, солесборников, минимизацию выноса мехпримесей, подбор и подготовку рабочего агента для ППД, ограничение водопритока к скважине, подавление биоценоза. На рассматриваемом объекте предлагаются именно такие методы предупреждения образования отложений солей. $\mathrm{K}$ химическим методам относится применение ингибиторов солеотложения, а также выбор «безопасных» жидкостей глушения [15, 16]. С целью защиты системы нефтесбора рекомендуется организовать подачу ингибитора солеотложений и необходимо подбирать эффективный ингибитор солеотложений для условий месторождений, осуществляющих сбор на НСП «Б» [17].

При этом ингибитор должен соответствовать общим требованиям для промышленного применения. Эффективность ингибирования солеотложения в условиях, максимально приближенных к реальным, совместимость с пластовой водой и использующимися водными жидкостями глушения, влияние на процесс промысловой подготовки нефти, оценка адсорбционно-десорбционных свойств на моделях, влияние на набухание водочувствительных глин и т. д. [18].

Была рассмотрена проблема образования отложения солей, проведен анализ этих отложений. Определено процентное содержание неорганической и органической частей осадков. Были выяснены причины образования отложений солей в системе сбора месторождения X, в напорных нефтепроводах с помощью анализа макрокомпонентного состава попутно-добываемых вод. Анализ показал, что в пробах попутно-добываемой воды содержится существенное количество ионов кальция и сульфат-ионов, которые могут быть причиной образования отложения солей. Произведен расчет коэф- 
фициента пересыщения $\varphi$ по методике Скилмена-Мак-Дональда-Стиффа. По полученным значениям можно сделать вывод, что в скважинах гипс может выпадать и в объеме, и на самой поверхности теплообмена.

В наши дни проблема, связанная с образованием отложения солей, является очень острой для

\section{СПИСОК ЛИТЕРАТУРЫ}

1. Применение механических методов предупреждения отложения солей в скважинах залежей / Ю.Н. Легаев, И.С. Ванюрихин, Д.В. Пищаев, Ф.А. Галиев, К.В. Валовский // Нефтяное хозяйство. - 2015. - № 7. - С. 58-60.

2. Бешагина Е.В., Можайская М.В. Подбор эффективного ингибитора солеотложения и его концентрации при эксплуатации месторождений / / Успехи современной науки и образования. 2016. - T. 5. - № 12. - C. 76-81.

3. Аксенов Д.А. Эксплуатация скважин в условиях солеотложения // Академический журнал Западной Сибири. - 2016. T. 12. - № 2. - C. 5.

4. Шангараева Л.А., Максютин А.В., Султанова Д.А. Способы предотвращения солеотложения при разработке и эксплуатации залежей нефти // Современные проблемы науки и образования. - 2015. - № 1. - С. 336.

5. Антониади Д.Г., Савенок 0.В. Проблема солеотложения - общие принципы и особенности конкретных решений // Политематический сетевой электронный научный журнал Кубанского государственного аграрного университета. - 2013. - № 87. C. 260-275. URL: http://ej.kubagro.ru/a/viewaut.asp?id=2734 (20.04.2019).

6. Повышение эффективности использования ингибиторов отложения солей / Ю.В Антипин., Н.Р. Яркеева, Г.Ш. Исланова, P.Р. Кашапов // Интервал. Передовые нефтегазовые технологии. - 2003. - № 8. - С. 65-67.

7. Пути повышения эффективности предотвращения образования отложений неорганических солей в скважинах / А.Ш. Сыртланов, Р.А. Фасхутдинов, Г.Ш. Шайдулин, Ю.В. Антипин, Н.Р. Яркеева // Нефтяное хозяйство. - 2002. № 4. - С. 59-61.

8. Кащавцев В.Е. Подбор ингибиторной защиты скважины от солеобразования при добыче нефти // Нефтепромысловое дело. 1993. - № 607. - C. 21-23.

9. Бриков А.В., Маркин А.Н. Организация системы борьбы с отложением солей на примере нефтяного месторождения Западной Сибири // Нефтепромысловое дело. - 2018. - № 4. C. $56-61$. нефтедобычи [19]. Она несет большие убытки нефтедобывающим предприятиям. Нужно заранее предупреждать образование отложений, выбирая методы предупреждения. Также немаловажен такой вопрос, как подбор эффективного ингибитора в борьбе с уже образовавшимися отложениями солей [20].

10. Кащавцев В.Е. Роль пластовых вод в процессе осадкообразования солей при добыче нефти // Нефть, газ и бизнес. - 2004. № 1. - C. $42-45$.

11. Оценка эффективности ингибирования солеотложения / И.Д. Эшметов, Ш.А. Кулдашева, В.П. Гуро, Д.С. Салиханова // Фундаментальные и прикладные исследования в современном мире. - 2016. - № 15. - С. 128-130.

12. Fighting scale - removal and preventing / M. Crabtree, D. Eslinger, F. Fletcher, M. Miller // Oilfield Review. - 2002. - V. 2. P. 52-73.

13. Jordan M., Mackey J. Scale control in deepwater fields: use interdisciplinary approach to control scale // World Oil. - 2006. V. 9. - P. 8-12.

14. Bybee K. Scale Cause in the Smorbukk Field // Journal of Petroleum Technology. - 2006. - V. 1. - P. 71.

15. Amiri M., Moghadasi J. Prediction the amount of barium sulfate scale formation in Siri oilfield using OLI ScaleChem Software // Asian Journal of scientific research. - 2010 - V. 3. - P. 230-239.

16. Radler M. Oil production, reserves increase slightly // Oil and Gas Journal. - 2006. - V. 47. - P. 20-21.

17. Christian L. Size distribution of Middle East fields and reserves growth issues draw focus // Oil and Gas Journal. - 2007. V. 34. - P. 36-41.

18. Belyadi H., Ebrahim F., Belyadi F. Hydraulic Fracturing in Unconventional Reservoirs. - Pittsburgh: Elsevier Science, 2016. $452 \mathrm{p}$.

19. Abass A. Corrosion inhibition of offshore oil and gas production facilities using organic compound inhibitors // Journal of Molecular Liquids. - 2017. - V. 248. - P. 775-808.

20. Experimental investigation of inhibitors injection to control salt precipitation using wetted wall column / S. Hosseini, M. Asemani, F. Esmaeilzadeh, D. Mowla // Journal of Petroleum Science and Engineering. - 2014. - V. 122. - P. 667-674.

Поступила 24.04.2019 2.

\section{Информация об авторах}

Яркеева H.P., кандидат технических наук, доцент кафедры разработки и эксплуатации нефтяных и газонефтяных месторождений Уфимского государственного нефтяного технического университета.

Галкова A.Ф., магистр кафедры разработки и эксплуатации нефтяных и газонефтяных месторождений Уфимского государственного нефтяного технического университета. 


\title{
ANALYSIS OF DEPOSITS OF INORGANIC SALTS IN THE SYSTEM OF COLLECTION OF NSP «B», BPS-5 «A»
}

\author{
Natalia R. Yarkeeva', \\ yarkeevan@yandex.ru \\ Alsu F. Galkova', \\ alsugalkova1995@mail.ru \\ 1 Ufa State Petroleum Technological University, \\ 1, Kosmonavtov street, Ufa, 450062, Russia.
}

Relevance. Currently, the problem of salt deposits formation is very relevant and important. Oil production becomes difficult with the advent of inorganic deposits, which are formed in the well bottom zone, and in the systems for collecting and preparing well products. The consequences of salt deposits are a decrease in the well productivity coefficient, which causes a significant loss of oil. Also, due to insufficient inflow, there is a risk of failure of downhole pumping equipment, a decrease in time between failures of this equipment appears due to occurrence of seizures of electric centrifugal pump and sucker rod pump valves. For these reasons, oil companies suffer significant losses, as large expenditures on measures to prevent and combat salt deposits become necessary.

The aim of the research is to study this problem in details; to identify sediment prevention and control methods; to determine whether a precipitate will fall out as a result of defining the coefficient of supersaturation, by the method of Skilmen-McDnald-Stiff; to analyze the studies in definition of sediments composition.

The methods. The Skilmen-McDnald-Stiff technique was used in calculations. The inorganic part of the sediments was determined by $X$-ray diffraction on a Shimadzu XRD-6000 powder diffractometer.

The results. Analysis of the results of determining the macro- and microcomponent composition of water showed that the samples of passing-extracted water taken from production wells and automated group metering installation of deposit X contain significant amounts of calcium ions and sulfate ions, which can lead to formation of insoluble salts, such as calcite and plaster. In the wells 5 and 311 , the supersaturation coefficient is 1 (there is supersaturation of formation water with gypsum). In these wells, gypsum has the ability to fall out both in volume and on the heat exchange surface itself. In the well 158 the supersaturation coefficient is 1 . With unsaturation or formation water, there will be no precipitation in the volume. However, on the heat exchange surface, due to partial evaporation, the solution is especially saturated with gypsum. Because of this, the gypsum is able to be postponed even with some undersaturation of the produced water with it - with a decrease in the coefficient to 0,9. It is necessary to prevent in advance gypsum deposits not to allow them complicating oil production. To prevent deposits formation it is necessary to select an effective inhibitor of scaling for conditions of deposits collecting at NSP «B». To protect the oil gathering system, it is recommended to organize the supply of a scale inhibitor.

Key words:

Deposits, sedimentation, inorganic salts, calcite, gypsum, scale inhibitor.

\section{REFERENCES}

1. Legai Yu.N., Vanyurikhin I.S., Bishaev D.V., Galiev F.A., Wallowski K.V. Use of mechanical methods of preventing salt deposits in wells reservoirs. Oil industry, 2015, no. 7, pp. 58-60. In Rus.

2. Beshagina E.V., Mozhaiskaya M.V. Selection of effective inhibitor of scaling and its concentration in the exploitation of deposits. Advances in modern science and education, 2016, no. 12, pp. 76-81. In Rus.

3. Aksenov D.A. Well operation in the conditions of salt deposition. Academic Journal of Western Siberia, 2016, vol. 12, no. 2, pp. 5. In Rus.

4. Shingareva L.A., Maksyutin A.V., Sultanov D.A. How to prevent sludge in the development and exploitation of oil deposits. $M o$ dern problems of science and education, 2015, no. 1, pp 336. In Rus.

5. Antoniadi D.G., Savenok 0.V. The problem of scaling - general principles and features of specific solutions. Polythematic network electronic scientific journal of the Kuban state agrarian University, 2013, no. 87, pp. 260-275. In Rus. Available at: http://ej.kubagro.ru/a/viewaut.asp? id=2734 (accessed: $20 \mathrm{Ap}$ ril 2019).

6. Antipin Yu.V., Yarkeeva N.R., Islanova G.Sh., Kashapov R.R. Increase of efficiency of use of inhibitors of salt deposits. Interval. Advanced oil and gas technologies, 2003, no. 8, pp. 65-67. In Rus.
7. Syrtlanov A.S., Faskhutdinov R.A., Shaydulin G.S., Antipin Yu.V., Yarkeeva N.R. Ways to improve the efficiency of preventing the formation of deposits of inorganic salts in wells. Oil industry, 2002, no. 4, pp. 59-61. In Rus.

8. Kasantsev V.E. Podbor ingibitornoy zashchity skvazhiny ot soleobrazovaniya pri dobyche nefti [Selection of inhibitory protection of wells from the salt formation in oil]. Oilfield business, 1993, no. 607, pp. 21-23.

9. Brikov A.V., Markin A.D. Organization of the system of salt Deposit control on the example of the oil field of Western Siberia. Oilfield business, 2018, no. 4, pp. 56-61. In Rus.

10. Kasantsev V.E. The role of reservoir water in the process of sedimentation of salts in the extraction of oil. Oil, gas and business, 2004, no. 1, pp. 42-45. In Rus.

11. Ashmetov I.D., Kuldashev S.A., Guro V.P., Salyanova D.S. Assessment of the effectiveness of inhibition of scaling. Fundamental and applied studies in the modern world, 2016, no. 15, pp. 128-130. In Rus.

12. Crabtree M., Eslinger D., Fletcher F., Miller M. Fighting scale removal and preventing. Oilfield Review, 2002, vol. 2, pp. 52-73.

13. Jordan M., Mackey J. Scale control in deepwater fields: use interdisciplinary approach to control scale. World Oil, 2006, vol. 9, pp. 8-12.

14. Bybee K. Scale Cause in the Smorbukk Field. Journal of Petroleum Technology, 2006, vol. 1, pp. 71.

15. Amiri M., Moghadasi J. Prediction the amount of barium sulfate scale formation in Siri oilfield using OLI ScaleChem Software. Asian Journal of scientific research, 2010, vol. 3, pp. 230-239. 
16. Radler M. Oil production, reserves increase slightly. Oil and Gas Journal, 2006, vol. 47, pp. 20-21.

17. Christian L. Size distribution of Middle East fields and reserves growth issues draw focus. Oil and Gas Journal, 2007, vol. 34, pp. $36-41$.

18. Belyadi H., Ebrahim F., Belyadi F. Hydraulic Fracturing in Un conventional Reservoirs. Pittsburgh, Elsevier Science, 2016. $452 \mathrm{p}$.
19. Abass A. Corrosion inhibition of offshore oil and gas production facilities using organic compound inhibitors. Journal of Molecular Liquids, 2017, vol. 248, pp. 775-808.

20. Hosseini S., Asemani M., Esmaeilzadeh F., Mowla D. Experimental investigation of inhibitors injection to control salt precipitation using wetted wall column. Journal of Petroleum Science and Engineering, 2014, vol. 122, pp. 667-674.

Received: 24 April 2019.

\section{Information about the authors}

Natalia R. Yarkeeva, Cand. Sc., associate professor, Ufa State Petroleum Technological University.

Alsu F. Galkova, master, Ufa State Petroleum Technological University. 